Supplement

\title{
Early Identification and Prevention of the Spread of Ebola in High-Risk African Countries
}

\author{
Lucy Breakwell, $\mathrm{PhD}^{1}$ \\ A. Russell Gerber, $\mathrm{MD}^{2}$ \\ Ashley L. Greiner, MD ${ }^{1}$ \\ Deborah L. Hastings, $\mathrm{MD}^{1}$ \\ Kelsey Mirkovic, $\mathrm{PhD}^{1}$ \\ Magdalena M. Paczkowski, PhD ${ }^{1}$ \\ Sekou Sidibe, $\mathrm{MPH}^{2}$ \\ James Banaski, MS 3 \\ Chastity L. Walker, $\mathrm{DrPH}^{2}$ \\ Jennifer C. Brooks, $\mathrm{MPH}^{3}$ \\ Victor M. Caceres, $\mathrm{MD}^{2}$ \\ Ray R. Arthur, $\mathrm{PhD}^{2}$ \\ Frederick J. Angulo, DVM, PhD 2 \\ ${ }^{1}$ Epidemic Intelligence Service, CDC \\ ${ }^{2}$ Division of Global Health Protection, Center for Global Health, CDC \\ ${ }^{3}$ Division of Emergency Operations, Office of Public Health Preparedness and Response, CDC
}

Corresponding author: Frederick J. Angulo, Division of Global Health Protection, Center for Global Health, CDC. Telephone: 404-639-5314; E-mail: FAngulo@cdc.gov.

\section{Summary}

In the late summer of 2014, it became apparent that improved preparedness was needed for Ebola virus disease (Ebola) in at-risk countries surrounding the three highly affected West African countries (Guinea, Sierra Leone, and Liberia). The World Health Organization (WHO) identified 14 nearby African countries as high priority to receive technical assistance for Ebola preparedness; two additional African countries were identified at high risk for Ebola introduction because of travel and trade connections. To enhance the capacity of these countries to rapidly detect and contain Ebola, CDC established the High-Risk Countries Team (HRCT) to work with ministries of health, CDC country offices, WHO, and other international organizations. From August 2014 until the team was deactivated in May 2015, a total of 128 team members supported 15 countries in Ebola response and preparedness. In four instances during 2014, Ebola was introduced from a heavily affected country to a previously unaffected country, and CDC rapidly deployed personnel to help contain Ebola. The first introduction, in Nigeria, resulted in 20 cases and was contained within three generations of transmission; the second and third introductions, in Senegal and Mali, respectively, resulted in no further transmission; the fourth, also in Mali, resulted in seven cases and was contained within two generations of transmission. Preparedness activities included training, developing guidelines, assessing Ebola preparedness, facilitating Emergency Operations Center establishment in seven countries, and developing a standardized protocol for contact tracing. CDC's Field Epidemiology Training Program Branch also partnered with the HRCT to provide surveillance training to 188 field epidemiologists in Côte d'Ivoire, Guinea-Bissau, Mali, and Senegal to support Ebola preparedness. Imported cases of Ebola were successfully contained, and all 15 priority countries now have a stronger capacity to rapidly detect and contain Ebola.

The activities summarized in this report would not have been possible without collaboration with many U.S and international partners (http://www.cdc.gov/vhflebolaloutbreaks/2014-west-africalpartners.html).

\section{Background}

In the late summer of 2014 , it became apparent that improved preparedness was needed for Ebola virus disease (Ebola) in at-risk countries surrounding the three West African countries that were most highly affected (Guinea, Sierra Leone, and Liberia). The potential for Ebola to spread from these countries to other countries in Africa was of particular concern. Côte d'Ivoire, Guinea-Bissau, Mali, and Senegal were considered at greatest risk for Ebola importation because each shared a land border with Guinea or Liberia. The World Health Organization (WHO) identified these four bordering countries and 10 others in the WHO Africa Region (Benin, Burkina Faso, Cameroon, Central African Republic, Ethiopia, The Gambia, Ghana, Mauritania, Niger, and Togo) as the highest priority countries for technical assistance for Ebola preparedness; two additional countries (Nigeria and Democratic Republic of the Congo) were identified as at high risk for Ebola introduction because of strong trade and travel links with the affected countries (1). 
Recognizing the importance of rapid response to an Ebola importation, CDC established the High-Risk Countries Team (HRCT) in the International Task Force of the CDC Ebola response in August 2014. Its purpose was to enhance the capacity of identified high-priority African countries to rapidly detect and contain an imported case of Ebola. To facilitate the enhancement of the capacity for rapid Ebola detection and containment, the Atlanta, Georgia-based HRCT, in close collaboration with CDC country offices in Africa, focused on building epidemiologic and laboratory capacity, particularly Ebola surveillance and alert systems, Ebola specimen transport, contact tracing, border/points-of-entry screening, and implementation of rapid response teams.

When the HRCT was deactivated in May 2015, CDC had provided technical assistance for Ebola preparedness to 15 of the 16 at-risk countries (the exception was the Central African Republic) (Figure 1). CDC also assigned staff to the WHO Africa Regional Office in Brazzaville, Congo, and WHO headquarters in Geneva, Switzerland. In-country members of the HRCT worked directly with ministry of health $(\mathrm{MoH})$ officials or persons who worked for organizations designated responsible for the country's Ebola preparedness activities. The team also collaborated with WHO and other international organizations, such as the International Organization for Migration, Médecins Sans Frontières (MSF), and the International Committee of the Red Cross. Key in-country partners included U.S. Embassy staff, particularly U.S. Agency for International Development and CDC country office staff.

CDC staff already had been working in nine of the 15 countries and were intensely involved in Ebola preparedness and response; seven of these countries (Cameroon, Democratic Republic of the Congo, Ethiopia, Ghana, Côte d'Ivoire, Mali, and Nigeria) had CDC country offices, and the two other countries (Benin and Senegal) had in-country CDC malaria resident advisors involved in the President's Malaria Initiative (Figure 1). Because CDC in-country staff already had built relationships with public health staff in their countries, they were able to more rapidly assist these countries with Ebola preparedness.

A total of 128 CDC staff provided in-country technical support to these countries and to WHO Africa Regional Office and WHO headquarters. An additional 30 CDC staff members in Atlanta supported personnel deployed in the field. Countries that received the highest levels of CDC in-country technical support were the three countries that had imported cases of Ebola: Nigeria, Senegal, and Mali.

\section{CDC Technical Assistance in Ebola Preparedness and Response}

\section{Nigeria}

On July 20, 2014, an airline passenger with symptoms consistent with Ebola (index case-patient) traveled from Liberia to Lagos, Nigeria, and subsequently was confirmed to have Ebola (2). Thirteen direct contacts of the index case-patient, including nine health care workers, contracted Ebola; these cases represent first-generation spread of Ebola in Nigeria (2). Three of these case-patients transmitted Ebola to other persons (second-generation spread), including a physician in Port Harcourt, Nigeria, who was infected after treating a patient who had traveled to Port Harcourt from Lagos seeking private care (2). An additional three persons who had contact with the Port Harcourt physician contracted Ebola, representing third-generation spread of Ebola in Nigeria (Figure 2). Ultimately, the July Ebola importation into Nigeria resulted in 20 cases (19 confirmed and one probable) and eight deaths (2).

Given the population and the international airline connections in Lagos, as well as the economic and geographic importance of Nigeria, the introduction of Ebola into Nigeria represented a critical juncture in the response to Ebola. Immediately after being notified about the index case, the Lagos State $\mathrm{MoH}$, with technical assistance from CDC Nigeria and the Nigerian Polio Eradication Program, activated an Ebola Incident Management (IM) center that eventually became the national Emergency Operations Center (EOC) (2). Within 72 hours after being notified of the index case, CDC personnel and Nigerian Field Epidemiology Training Program (FETP) staff previously assisting the $\mathrm{MoH}$ with polio elimination were deployed to provide technical assistance to Nigeria's $\mathrm{MoH}$ and were incorporated into the EOC (2). The EOC in Lagos was built on an existing IM structure, developed as part of the Nigerian Polio Eradication Program (2,3). A major partner in the response in Nigeria was the FETP, which facilitated field work, particularly contact tracing. After Ebola was confirmed in Port Harcourt, an EOC was established there.

Approximately 890 persons who had been exposed to Ebola (contacts) were identified and monitored, 19,000 home visits were conducted, and 150,000 airline passengers were screened in Nigeria $(2,3)$. CDC team members were involved in planning, health communication, infection control, and surveillance, as well as in coordinating support from other sources (2). WHO declared Nigeria Ebola-free on October 20, 2014. 


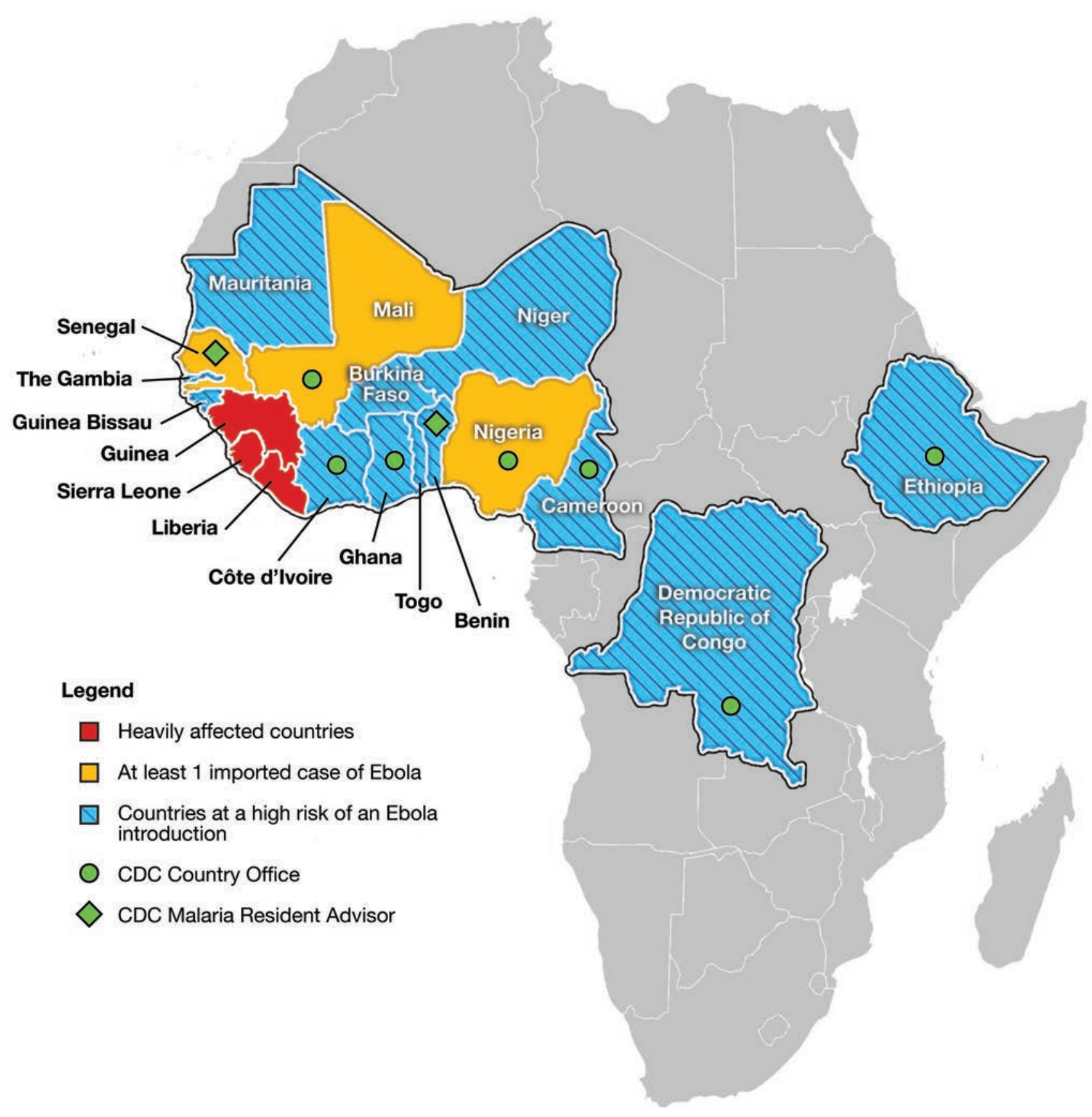

Abbreviation: Ebola $=$ Ebola virus disease.

* The High-Risk Countries Team was active from August 2014 through May 2015.

\section{Senegal}

Seven weeks into the Ebola outbreak in Nigeria, on August 29, 2014, Senegal confirmed its first Ebola case in a student aged 21 years who had traveled from Guinea in mid-August to visit family in Dakar, Senegal (index case-patient) (4). At the request of Senegal's $\mathrm{MoH}, \mathrm{CDC}$ quickly deployed staff, who partnered with the CDC malaria resident advisor in-country to assist the $\mathrm{MoH}$ with rapid Ebola containment through robust contact tracing, including 21-day active monitoring. The HRCT, which was developed shortly before cases in Senegal were recognized, facilitated the CDC response. A total of 74 contacts of the index case-patient were identified and followed through the 21-day monitoring period (4). No further Ebola transmission occurred in Senegal from this case (Figure 2) (4). 
FIGURE 2. Number of Ebola cases for each generation of transmission following each importation of Ebola - Nigeria, Senegal, and Mali, July 2014-January 2015*

\section{Generation of transmission}

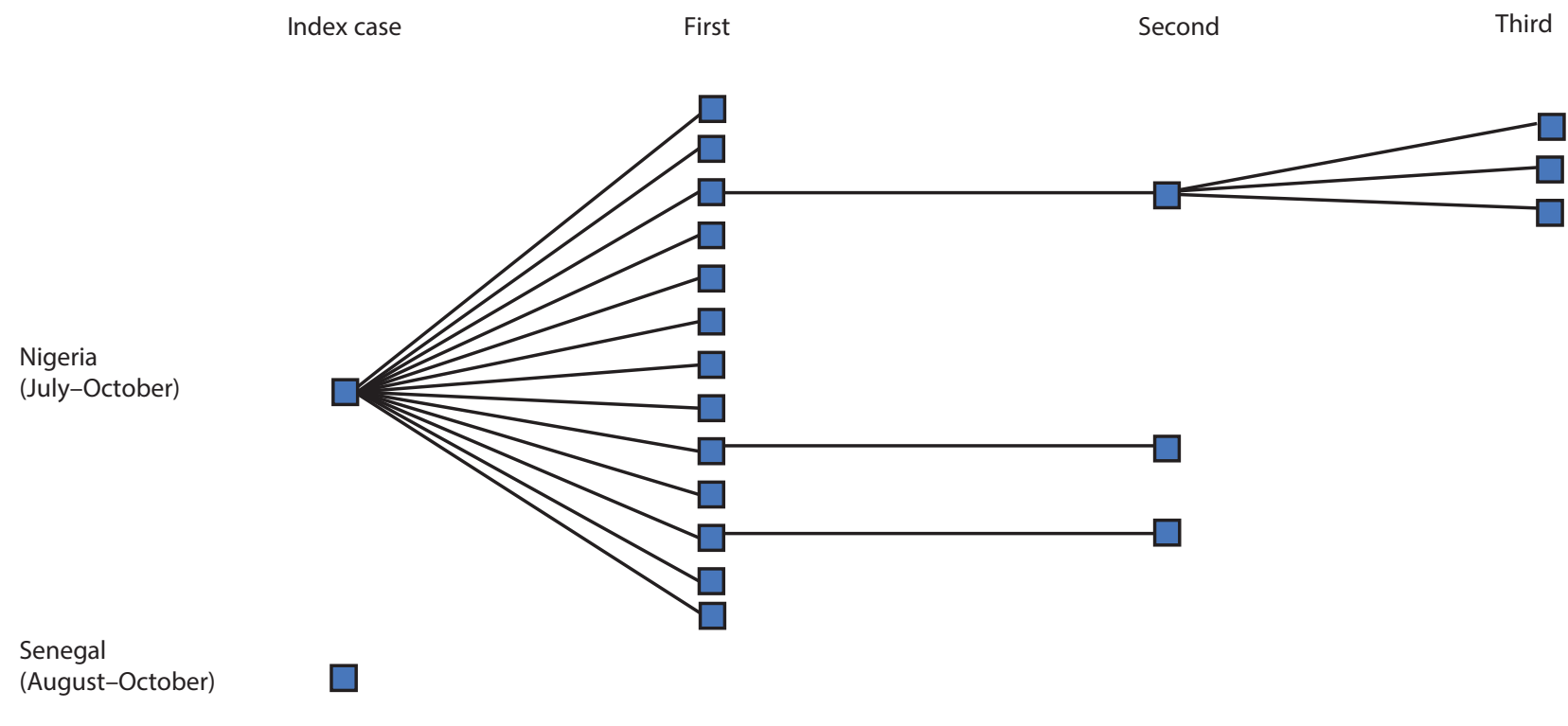

Mali Case 1

(October-January)

Mali Case 2

(October-January)

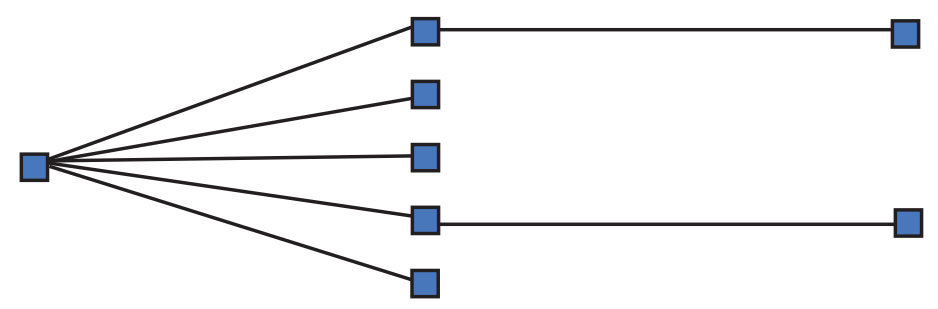

One case

Transmission

Abbreviation: Ebola = Ebola virus disease.

* The World Health Organization declared Nigeria free of Ebola on October 20, 2014; Senegal on October 17, 2014; and Mali on January $18,2015$.

The Dakar airport, a major West African hub, was a critical corridor for transporting aid into and out of the countries that were most heavily affected. Before the Ebola importation, Senegal no longer permitted air travel to or from Senegal and Guinea, Liberia, or Sierra Leone, which limited the transport of critical supplies into the countries that were heavily affected. CDC provided point-of-entry screening technical assistance at Dakar's airport, and this assistance contributed to the creation of an "air corridor" for humanitarian assistance whereby vital supplies and personnel could be transported to Liberia via the Dakar International Airport. CDC also assessed Senegal's Ebola surveillance system and provided recommendations to strengthen the system. WHO declared Senegal Ebola-free on October 17, 2014.

\section{Mali}

Mali confirmed its first imported Ebola case on October 20, 2014 (5). The index case-patient was a girl aged 2 years who 
traveled from Guinea to Kayes, Mali, transiting through Bamako, Mali's capital (5). Members of the HRCT, who were already in-country supporting a WHO Ebola preparedness mission, assisted Mali MoH staff with the response by drafting standard operating procedures and contact tracing guidelines. They also helped to institute an IM structure. No subsequent transmission occurred in Mali from this Ebola importation (Figure 2).

On November 10, 2014, Mali was notified of a second Ebola importation. This index case-patient was a man aged 70 years from Guinea who arrived at a Bamako clinic on October 25 with symptoms consistent with Ebola (Ø). The case investigation, immediately initiated by Malia's $\mathrm{MoH}$, revealed that this man did not share an epidemiologic link with the index case-patient of the first Ebola importation (G). Concern about the potential spread of Ebola in Bamako led to immediate deployment of additional CDC staff, who provided technical assistance for contact tracing, active surveillance, and border/points-of-entry screening. The team collaborated with Mali's $\mathrm{MoH}$ and WHO to identify 332 contacts of the index case-patient of the second importation; $93 \%$ of these persons completed 21-day active monitoring without missing a daily visit by the contact tracing team. The Ebola outbreak from the second Ebola importation was controlled within two generations of transmission. Five firstgeneration cases and two second-generation cases occurred in Mali; all second-generation cases were identified through active monitoring (Figure 2) (G). WHO declared Mali Ebola-free on January 18, 2015.

\section{Guidance on Contact Tracing}

CDC has continuously emphasized the importance of contact tracing as the single most effective tool for containing imported Ebola cases (7). As part of response and preparedness training, CDC supported development of national and local contact tracing guidelines and provided contact tracing training, particularly for rapid response teams. The rapid identification and isolation of contacts with symptoms consistent with Ebola reduces the risk for exposure to other persons, effectively breaking chains of transmission and halting Ebola transmission (7). However, contact tracing is effective only if it is initiated immediately after a case is identified and it is performed consistently and comprehensively.

Implementing and managing contact tracing during the 2014-2016 Ebola epidemic in West Africa posed serious challenges, including lack of a standardized approach. In response, CDC created a guidance document that detailed a systematic method for contact tracing implementation and management, "CDC Methods for Implementing and Managing Contact Tracing for Ebola Virus Disease in
Less-Affected Countries" (8). The content derived from responders' experiences supporting MoHs in Ebola preparation in the high-risk countries, as well as through the responders' direct involvement in contact tracing in the affected countries.

Team members also partnered with WHO to create joint comprehensive contact tracing guidelines applicable to all countries. These guidelines expanded on the previously published CDC document and WHO Africa Region's "Contact Tracing During an Outbreak of Ebola Virus Disease" guideline, detailing the contact tracing process, addressing common challenges, and describing contact tracing monitoring and evaluation methods $(7,8)$. The joint guidelines are intended to support contact tracing during the current epidemic and to operate as guidelines to prepare for and address future Ebola outbreaks.

\section{Additional Activities and Training for Ebola Preparedness}

In addition to providing contact tracing technical support and training to 450 persons, CDC trained approximately 1,500 persons on infection prevention and control, 300 on pointof-entry screening, and 120 on the Epi Info database used for Ebola surveillance. CDC developed guidelines, standard operating procedures, forms, and protocols for point-of-entry screening, Ebola surveillance, alert planning, preparedness, and 72-hour rapid response. CDC also facilitated introduction of the Emergency Management Development Team, which enabled initiation of public health emergency management capacity development, including development of EOCs, in seven high-risk countries: Cameroon, The Gambia, Ghana, Côte d'Ivoire, Mali, Nigeria, and Senegal.

Beginning in January 2015, to further strengthen field epidemiology capacity at all levels of the public health systems in West Africa, CDC's FETP Branch partnered with the CDC HRCT and the MoHs in Guinea-Bissau, Côte d'Ivoire, Mali, and Senegal; WHO Training Programs in Epidemiology and Public Health Interventions Network; and the African Field Epidemiology Network to implement Surveillance Training for Ebola Preparedness (STEP) (9), a 5-week program designed to rapidly strengthen surveillance skills among surveillance officers in districts bordering Ebola-affected countries.

STEP combined the Integrated Disease Surveillance and Response framework, widely used in Africa, with the FETP model of mentorship and field work. The training has three phases: 1) 1 week of classroom instruction about basic surveillance data analysis, interpretation, and reporting, including an Ebola-focused day covering surveillance case definitions and contact tracing; 2) a 3-week mentored field experience; and 3) a 3-day workshop on field work. During 
the field work component, participants visit surveillance sites in their home districts to audit data quality. Participants from highest risk districts, such as border districts or potential point-of-entry districts, are equipped with cell phones to report through a daily short message service (text message) the number of new suspected Ebola cases from the previous day. Data are uploaded in real time by using a Web-based mobile platform.

A total of 188 participants have been trained in STEP: 56 participants from 25 districts in Côte d'Ivoire (two sequential cohorts), 53 participants from 13 regions in GuineaBissau (two cohorts), 52 participants from 21 districts in Senegal (two cohorts), and 27 participants from 10 districts in Mali (one cohort). In addition to surveillance officers, STEP participants included nurses, laboratory technicians, statisticians, and chief medical officers.

CDC's partners have widely acknowledged that STEP provided critically needed field epidemiology training. STEP is evaluated 3-6 months after each training to assess changes in surveillance practice by using indicators collected at the start of each training. Experience gained during the Ebola response indicates that the STEP training model could be adapted to rapidly scale up surveillance capacity in future epidemics.

\section{Conclusion}

Members of the CDC HRCT, in partnership with MoHs and WHO, provided technical assistance for Ebola preparedness through in-country and headquarters support that assisted with the rapid containment of several imported Ebola cases. In collaboration with many partners, particularly CDC's FETP Branch, CDC supported development of the public health workforce in high-risk countries by providing field epidemiology trainings and enhanced in-country future response capabilities by facilitating development of IM capacity.

In addition to building country-specific epidemiology and surveillance capacity, country and regional capacity in West Africa needs to be strengthened. National borders do not prevent the spread of disease, as evidenced by the importations of Ebola in this epidemic. Mechanisms for information sharing to effectively address future outbreaks also need enhancement. As described in the newly launched Global Health Security Agenda (10), such public health capacity building and information sharing are essential worldwide for all countries to meet the goal of the International Health Regulations (11) to rapidly detect and respond to public health events of international importance.

\section{Acknowledgments}

High-Risk Countries Team: Cleopatra Adedeji, Walter Alarcon, Kristina Angelo, Ronke Apata, Grace Appiah, Nicole Stehling Ariza, Rene Arrazola, Carmen Arriola, Angel Aviles, Daniel Baden, Kip Baggett, Ezra Barzilay, Oleg Bilukha, Denise Borntrager, Eric Brenner, Vance Brown, Lauren Brown Burness, Gary Burnette, Erica Bushong, Andrea Carcelen, Bryan Christensen, Angela Cleveland, Gary Cobb, Adam Cohen, Dana Cole, Deborah Conner, Emily Cramer, James Crockett, Cheryl Cunningham, Dave Daigle, Subrat Das, Kristin Delea, Panayotta Delinois, Andrew Demma, Yvette Diallo, Fabien Diomande, Timothy Doyle, Shahul Ebrahim, Lina Elbadawi, Lisa Esapa, T'Rhonda Flagg, Ted Forbes, Daniel Frank, Yolonda Freeman, Nicholas Gaffga, Ruth Cooke Gibbs, Sherry Gilbert, Adrienne Gill, Runa Gokhale, Cheri Grigg, Marta Guerra, Abdou Gueye, Rajni Gunnala, Rana Hajjeh, Jessica Hancock-Allen, Jeff Hanson, Jennifer Harris, Donald Haverkamp, Wendy Heaps, Katrina Hedberg, Morgan Hennessey, Katherine Hills, Christopher Hsu, David Hunter, Charlotte Kabore, Melissa Kadzik, Amelia Kasper, Julia Kibunja, Craig Kiebler, Cara Bicking Kinsey, Andrew Klevos, Nancy Knight, Judy Kruger, Pascale Krumm, Prathit Kulkarni, Jessie Legros, Jacquelyn Lickness, Xia Lin, Ulzii Orshikh Luvsansharav, Alexandre Macedo De Oliveira, Jennifer MacFarquhar, Frank Mahoney, Jean-Marie Maillard, Jessica Marcinkevage, Lise Martel, Chad Martin, Almea Matanock, Jay McAuliffe, Andrea McCollum, Amanda McGurn, Claire Midgley, Rajal Mody, Benjamin Monroe, Samantha Morgan, Leah Moriarty, Rupa Narra, Ryan Novak, Thai-An Ngyuen, Edith Nyangoma, Ikwo Oboho, Monique Tuyisenge Onyegbula, Chantelle Owens, Julia Painter, Benjamin Park, Prabasaj Paul, Leonard Peruski, Reine Phillips, Meredith Pinto, Raoult Ratard, Mary Reynolds, Andre Riggins, Tomas Rodriguez, Kyle Roesler, Keysha Ross, Joaquin Rueda, Michelle Russell, Peter Rzeszotarski, Stephanie Salyer, Erin Sauber-Schatz, Colin Schwensohn, Julie Sinclair, Lee Smith, Craig Steffens, Aimee Summers, Philana Swann, David Swerdlow, Pamela Talley, Jennifer Thomas, Brenna VanFrank, Marietijie Venter, John Vertefeuille, Antonio Vieira, Tyson Volkmann, Neil Vora, Allison Walker, Malaika Washington, Emily Weston, Racquel Williams, Nana Wilson, Jacklyn Wong, Hsiu Wu, Weigong Zhou.

CDC staff in-country offices: Benin: Peter Thomas; Cameroon: Omotayo Bolu, Els Mathieu, Gordon Okpu; Côte d'Ivoire: Abdou Gueye, Fazle Khan, Stefan Weir, Therese Wingate; Democratic Republic of the Congo: Yassa Ndjakani, Kassim Sidibe; Ethiopia: Berhanu Amare, Linda Boulanger, Clare Dykewicz, Jeff Hanson, Theresa Kanter, Joseph Malone, Brent Wolff; Ghana: Philips Ricks, Cecil Threat, Celia Woodfill; Mali: Varough Deyde, Jacques Mathieu, Jules Mihigo, Adama N'dir; Nigeria: Catherine Avery, Pauline Harvey, Pratima Raghunathan; Senegal: Julie Thwing.

Graphics technical assistance: Thomas Nagle. 


\section{References}

1. World Health Organization. Ebola virus disease preparedness: taking stock and moving forward. Geneva, Switzerland: World Health Organization; 2015. http://www.who.int/csr/resources/publications/ ebola/preparedness-meeting-report/en/

2. Shuaib F, Gunnala R, Musa EO, et al. Ebola virus disease outbreakNigeria, July-September 2014. MMWR Morb Mortal Wkly Rep 2014;63:867-72.

3. Frieden TR, Damon IK. Ebola in West Africa-CDC's role in epidemic detection, control, and prevention. Emerg Infect Dis 2015;21:1897-905. http://dx.doi.org/10.3201/eid2111.150949

4. Mirkovic K, Thwing JD, Diack PA. Imported Ebola virus diseaseSenegal, 2014. MMWR Morb Mortal Wkly Rep 2014;63:873-4.

5. World Health Organization. Mali confirms its first case of Ebola. Ebola situation assessment: 24 October 2014. Geneva, Switzerland: World Health Organization; 2014. http://www.who.int/mediacentre/news/ ebola/24-october-2014/en/

6. World Health Organization. Mali confirms its second fatal case of Ebola virus disease. Ebola situation assessment: 12 November 2014. Geneva, Switzerland: World Health Organization; 2014. http://www.who.int/ mediacentre/news/ebola/24-october-2014/en/
7. World Health Organization. Contact tracing during an outbreak of Ebola virus disease. Geneva, Switzerland: World Health Organization; 2015. http://www.who.int/csr/resources/publications/ebola/contacttracing/en/

8. CDC. CDC methods for implementing and managing contact tracing for Ebola virus disease in less-affected countries. Atlanta, GA: US Department of Health and Human Services, CDC; 2015. http://www. cdc.gov/vhf/ebola/pdf/contact-tracing-guidelines.pdf

9. CDC. CDC launches FETP-STEP in Cote d'Ivoire and other high-risk unaffected countries in West Africa. Atlanta, GA: US Department of Health and Human Services, CDC; 2015. http://www.cdc.gov/ globalhealth/stories/fetp_cote-d-ivoire.htm

10. Heymann DL, Keizo Takemi LC, Fidler DP, et al. Global health security: the wider lessons from the west African Ebola virus disease epidemic. Lancet 2015;385:1884-901.

11. World Health Organization. International Health Regulations. Geneva, Switzerland: World Health Organization; 2016. http://www.who.int/ topics/international_health_regulations/en/ 